This article is licensed under the Creative Commons Attribution-NonCommercial 4.0 International License (CC BY-NC) (http://www.karger.com/Services/OpenAccessLicense). Usage and distribution for commercial purposes requires written permission.

\title{
Sarcoidosis of the Intra- and Extrahepatic Bile Ducts with Concomitant Cholangitis in a Patient with Ulcerative Colitis
}

\author{
Ahmad Fasel Jebran ${ }^{a} \quad$ Wolfgang E. Schmidt ${ }^{b}$ Alisan Kahraman ${ }^{c}$ \\ Ali Canbay ${ }^{d}$ Kerem Bulut ${ }^{a}$ \\ ${ }^{a}$ Clinic for Internal Medicine and Gastroenterology, St. Clemens-Hospital Geldern, \\ Geldern, Germany; ${ }^{b}$ St. Josef Hospital Bochum, Hospital of Ruhr-University, Department of \\ Internal Medicine, Bochum, Germany; 'Department of Gastroenterology and Hepatology, \\ University Clinic of Essen, Essen, Germany; ${ }^{d}$ Department of Gastroenterology, Hepatology \\ and Infectious Diseases, Otto-von-Guericke University, Magdeburg, Germany
}

\section{Keywords}

Ulcerative colitis - Primary sclerosing cholangitis - Inflammatory bowel disease - Sarcoidosis . IgG4 cholangitis

\begin{abstract}
Cholangitis in patients with ulcerative colitis (UC) can lead to misdiagnosis of primary sclerosing cholangitis (PSC). Furthermore, it can mimic cholangiocellular carcinoma, which also can lead to inappropriate and potentially harmful treatment of the patient. An 18-year-old male patient with known UC presented with pain in his right upper abdomen and elevation of the cholestatic liver enzymes (alkaline phosphatase: $197 \mathrm{U} / \mathrm{L}, \mathrm{Y}$-glutamyltransferase: $229 \mathrm{U} / \mathrm{L}$ ) and increased inflammatory parameters (leukocytosis and $\mathrm{CrP}$ of $13.6 \mathrm{mg} / \mathrm{L}$ ). Magnetic resonance cholangiopancreatography revealed unclear stenosis in the bifurcation of the main hepatic bile
\end{abstract}




\section{Case Reports in Gastroenterology}

Case Rep Gastroenterol 2019;13:153-158

DOI: $10.1159 / 000497470$

(c) 2019 The Author(s). Published by S. Karger AG, Base www.karger.com/crg

Jebran et al:: Sarcoidosis of the Intra- and Extrahepatic Bile Ducts with Concomitant Cholangitis in a Patient with Ulcerative Colitis

duct as well as in the prepapillary bile duct. Ultrasound (US) examination and endoscopic retrograde cholangiopancreatography showed dilatation of the intra -and extrahepatic bile ducts, which raised the suspicion of PSC. US image with dilated intra- and extrahepatic dilatation of the bile duct was also suggestive for autoimmune cholangitis. However, serum analysis revealed an elevated soluble interleukin-II receptor $(1,305 \mathrm{U} / \mathrm{mL})$, while immunoglobulin $\mathrm{G} 4$ was within normal ranges. Liver biopsy demonstrated hepatic inflammation and presence of granulomatous cells within the portal fields - convenient to sarcoidosis. After starting treatment with steroids, we observed a rapid clinical response with improvement of the dilated bile ducts and decrease of the initially elevated cholestatic liver enzymes. Sarcoidosis within the bile duct is a rare condition. Steroids are the treatment of choice and - along with the histology - are furthermore helpful to differentiate between several potential differential diagnoses like lgG4 cholangitis, primary biliary cholangitis, or PSC.

(C) 2019 The Author(s)

Published by S. Karger AG, Basel

\section{Introduction}

Primary sclerosing cholangitis (PSC) is an idiopathic, chronic hepatobiliary disorder characterized by inflammation with progressive obliterative fibrosis and focal dilatation of the intrahepatic and/or extrahepatic bile ducts, which can lead to biliary cirrhosis and end-stage liver disease [1]. PSC is more common in Caucasian male patients and has a strong association with inflammatory bowel disease, especially ulcerative colitis (UC). The incidence of PSC is given with 1.11/100,000 in adults [2]. There are reports that show $20 \%$ of patients to be asymptomatic and only diagnosed on routine screening revealing abnormal cholestatic liver enzymes [3, 4].

Sarcoidosis - in contrast - is an inflammatory systemic disease that typically occurs in two or more organs at the same time (e.g., lung, heart). In more than $90 \%$ of the cases, the lung is the main affected organ. A typical characteristic is the histological finding of non-caseating epithelioid granulomas in biopsies [5]. Similar to PSC, etiology of sarcoidosis is still unclear.

The following case shows how - compared to PSC - an easily treatable differential diagnosis like sarcoidosis can mimic symptoms of PCS when bile ducts are affected. The mechanism for this observation is based on the compression within the bile ducts due to inflammatory swelling with consecutive induction of a stenosis suggesting an image similar to stenosis in PSC patients.

\section{Case Report}

An 18-year-old Caucasian male was presented as an outpatient to our hospital. The patient's complaints were abdominal pain in the right upper abdomen for 6 weeks. Moreover, cholestatic liver enzymes (alkaline phosphatase [AP] and $\gamma$-glutamyltransferase $[\gamma$-GT]) were also elevated. The patient developed vomiting and his leukocytes and $\mathrm{CrP}$ level increased. In 2015, he was diagnosed with (pan-)UC. He was in clinical remission and had no signs of a flare.

Laboratory findings for autoimmune hepatitis (ANA, LKM and SLA), primary biliary cholangitis (PBC) (AMA with subtype $\mathrm{M}_{2}$ ), PSC ( $\mathrm{x}$ - and p-ANCA), and finally IgG4 in serum were 


\section{Case Reports in Gastroenterology}

Case Rep Gastroenterol 2019;13:153-158

DOI: $10.1159 / 000497470$

(c) 2019 The Author(s). Published by S. Karger AG, Base www.karger.com/crg

Jebran et al:: Sarcoidosis of the Intra- and Extrahepatic Bile Ducts with Concomitant Cholangitis in a Patient with Ulcerative Colitis

negative. X-ray of his thorax and also echocardiography were normal. We only found a mild hyperinflation in the lung testing. Ultrasound (US) examination of the liver revealed dilatation of the main bile duct (DHC) of $12 \mathrm{~mm}$ with also irregularly dilated intrahepatic bile ducts with thickening of the wall resulting in a rich echo signaling of the duct wall. The rest of the liver parenchyma showed no pathologies. The following MR examination of the bile ducts and the pancreatic duct (magnetic resonance cholangiopancreatography) demonstrated a questionable stenosis in the prepapillary section of the DHC with concomitant narrowing of the intrahepatic bile ducts and slight enlargement of lymph nodes in the hepatic hilus and parapancreatic space. A typical finding for PSC was not described. However, endoscopic retrograde cholangiopancreatography revealed narrowed intrahepatic bile ducts, which suggested PSC. Interestingly, these findings were also present in the bifurcation of the DHC (Fig. 1). Brush cytology from the distal part of the bile duct showed a nonspecific acute inflammation. Liver biopsy was performed under sonographic control from the right liver lobule.

After liver biopsy, steroid treatment with $30 \mathrm{mg}$ prednisolone orally per day was initiated with the intention to treat a possible IgG4-associated cholangitis. Following this, a quick response to treatment occurred. All initially increased laboratory findings normalized as shown in Table 1 for total bilirubin, $\gamma$-GT, AP, ASAT, and finally, ALAT. His pain in the right upper abdomen completely disappeared and US examination after 4 days of treatment revealed a significant narrowing of the formerly enlarged bile ducts as well of the intra- and extrahepatic bile ducts (Fig. 2).

Histology of the liver specimen (Fig. 3) showed no signs of PSC. In contrast, further workup suggested PBC. Moreover, differential diagnosis suggested also a possibility for hepatic sarcoidosis. However, AMA autoantibody was negative, while surprisingly, soluble interleukin-II receptor was markedly elevated with 1,305 U/mL (reference $<623 \mathrm{U} / \mathrm{mL}$ ) indicating a possibility for sarcoidosis. Because of this finding and due to a quick response to steroid treatment (decrease of cholestatic parameters, good clinical response, diminishing of abdominal pain, and significant decrease of the diameters of the bile ducts in US control), we excluded the possible diagnosis of PBC and continued steroid treatment of sarcoidosis manifested within the bile ducts.

\section{Discussion}

Sarcoidosis is a rare disease with a prevalence of 46/100,000 in Germany. This disease is characterized by granulomatosis of various organs of unknown etiology, which mostly occurs (about 90\%) within the lung and the lymphatic system. The liver and the bile ducts are involved in approximately $15-20 \%$ of the cases. Misdiagnosis can lead to misinterpretation of the findings as a malignant lesion, e.g., as a cholangiocellular carcinoma [6]. Furthermore, these findings can also lead to the misdiagnosis of PSC [7].

In our case, diagnosis of UC was known before and treated with E. coli Nissle 1917 due to intolerance to azathioprine and mesalazine. Indeed, the underlying UC suggested an association with PSC. Successful treatment with steroids and elevated levels of interleukin-II receptor as well as the histological findings of epithelioid-cellular granuloma with inflammation within the portal fields suggested involvement of the bile ducts caused by the assumed diagnosis of sarcoidosis. The standard of care therapy is systemic steroid treatment (prednisolone 0.5 
$\mathrm{mg} / \mathrm{kg}$ ). Only in case of neurosarcoidosis are higher doses of steroids needed. In case of nonresponse, methotrexate or azathioprine is suggested. In case of unsuccessful treatment, there is consensus that anti-TNF- $\alpha$ (infliximab or adalimumab) can be considered as an effective alternative. Duration of treatment is at least 1 year. Although treatment with anti-TNF- $\alpha$ in Germany would be an off-label use for the treatment of sarcoidosis [8], our patient also suffered from UC, which can be treated with anti-TNF- $\alpha$. Following therapy, it is recommended to closely monitor AP, $\gamma$-GT, and total bilirubin every 8-12 weeks.

In summary, our treatment as presented above is another reasonable option for patients with bile duct stenosis in case of sarcoidosis. Liver biopsy should be considered as gold standard in any case of suspicious condition and unclear diagnosis, especially when potentially invasive therapy is considered next.

\section{Acknowledgements}

The assistance of medical student Ms. Dilan Bulut is appreciated.

\section{Statement of Ethics}

The patient gave his informed consent before publication.

\section{Disclosure Statement}

All authors have nothing to declare.

\section{References}

1 Chapman R, Fevery J, Kalloo A, Nagorney DM, Boberg KM, Shneider B, et al.; American Association for the Study of Liver Diseases. Diagnosis and management of primary sclerosing cholangitis. Hepatology. 2010 Feb;51(2):660-78.

2 Kaplan GG, Laupland KB, Butzner D, Urbanski SJ, Lee SS. The burden of large and small duct primary sclerosing cholangitis in adults and children: a population-based analysis. Am J Gastroenterol. 2007 May;102(5):1042-9.

3 Miloh T, Arnon R, Shneider B, Suchy F, Kerkar N. A retrospective single-center review of primary sclerosing cholangitis in children. Clin Gastroenterol Hepatol. 2009 Feb;7(2):239-45.

4 Feldstein AE, Perrault J, El-Youssif M, Lindor KD, Freese DK, Angulo P. Primary sclerosing cholangitis in children: a long-term follow-up study. Hepatology. 2003 Jul;38(1):210-7.

5 Baughman RP, Selroos O, Gibson PG, et al. Evidence-based approach to treatment of sarcoidosis. EvidenceBased Respiratory Medicine. Oxford: BMJ Books Blackwell; 2005. pp. 491-508.

6 Suzuki K, Morise Z, Furuta S, Tanahashi Y, Takeura C, Kagawa T, et al. Hepatic sarcoidosis mimicking hilar cholangiocarcinoma: case report and review of the literature. Case Rep Gastroenterol. 2011 Apr;5(1):152-8.

7 Tombazzi C, Waters B, Ismail MK, Sylvestre PB, Martinez-Hernandez A, Riely CA. Sarcoidosis mimicking primary sclerosing cholangitis requiring liver transplantation. Ann Hepatol. 2008 Jan-Mar;7(1):83-6.

8 Prasse A. Diagnosis, Differential diagnosis and Therapy of Sarcoidosis. Dtsch Arztebl Int. 2016 Aug 22;113(33-34):565-74. 


\section{Case Reports in Gastroenterology}

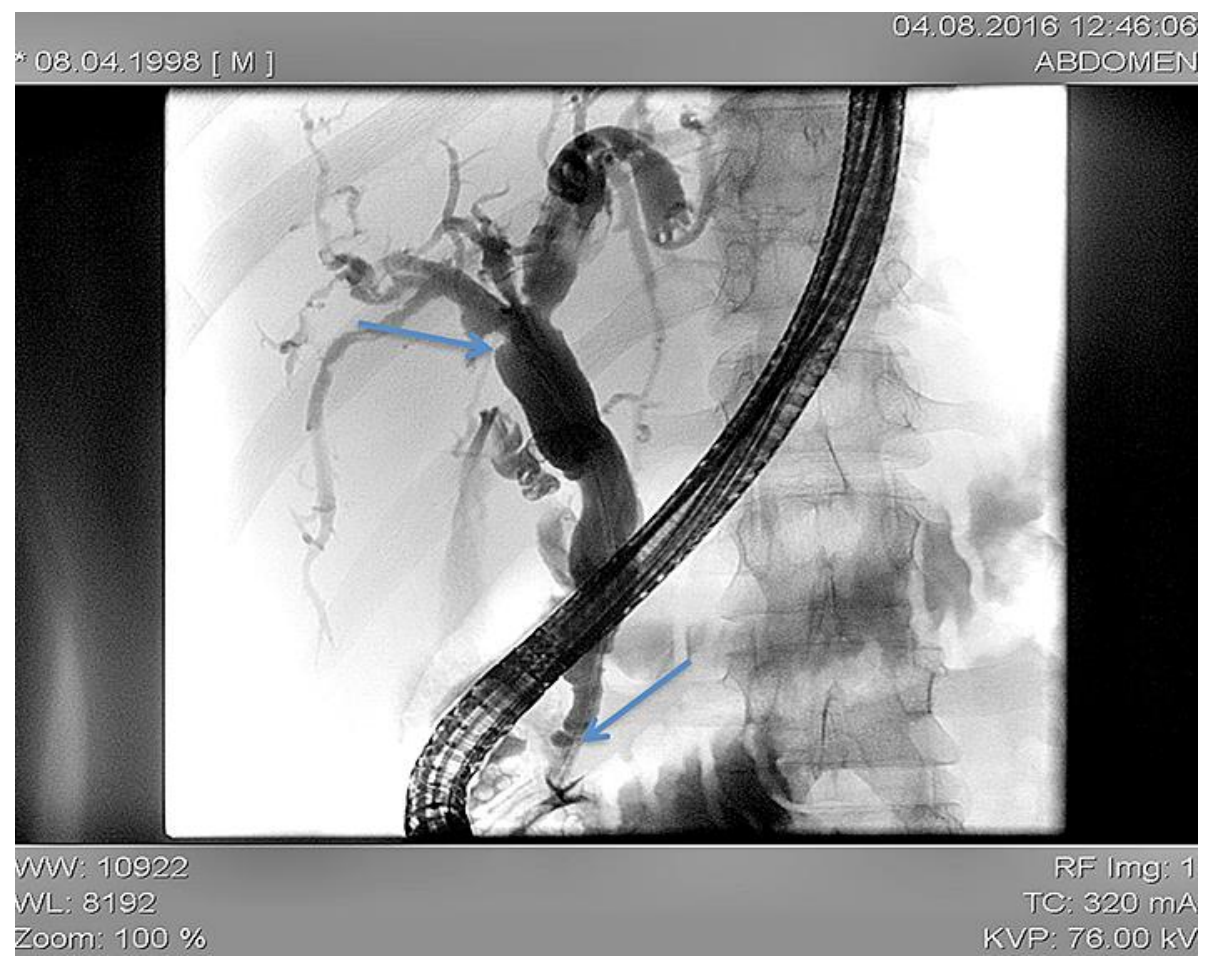

Fig. 1. Endoscopic retrograde cholangiopancreatography demonstrating constriction of the main duct bifurcation and the prepapillary region (marked with arrows).
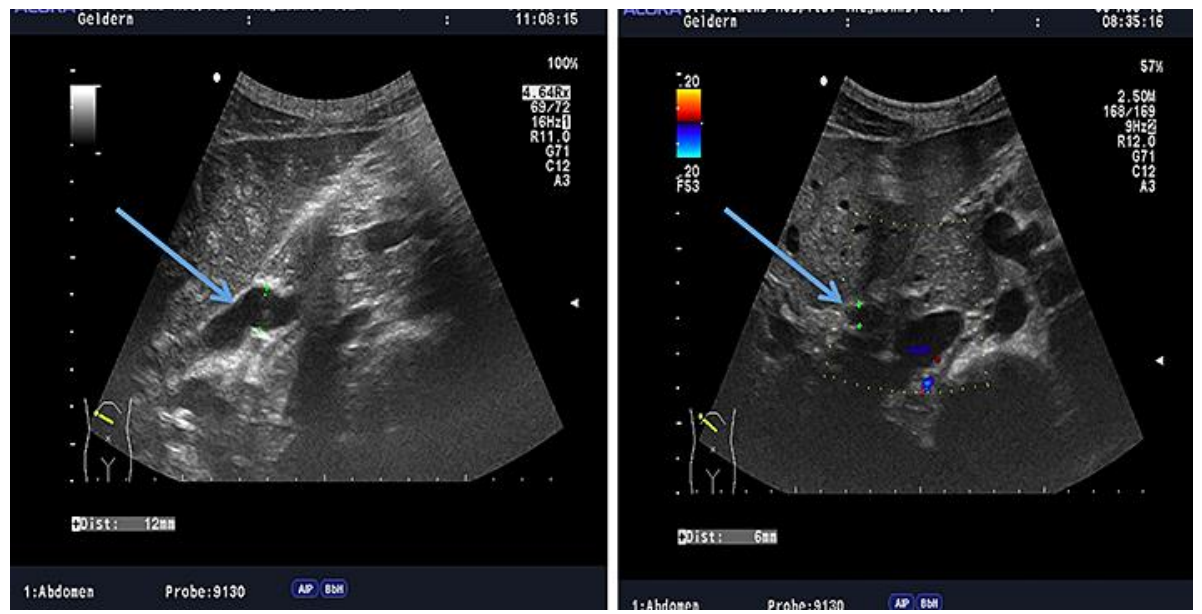

Fig. 2. Diameter of the main bile duct before prednisolone therapy initially measuring $12 \mathrm{~mm}$ (left panel) and following 4 days of prednisolone therapy with significant reduction to $6 \mathrm{~mm}$ (right panel). 


\section{Case Reports in Gastroenterology}

\begin{tabular}{l|l}
\hline Case Rep Gastroenterol 2019;13:153-158 \\
\hline DOI: 10.1159/000497470 & $\begin{array}{l}\text { (c) 2019 The Author(s). Published by S. Karger AG, Basel } \\
\text { www.karger.com/crg }\end{array}$ \\
\hline
\end{tabular}

Jebran et al.: Sarcoidosis of the Intra- and Extrahepatic Bile Ducts with Concomitant

Cholangitis in a Patient with Ulcerative Colitis

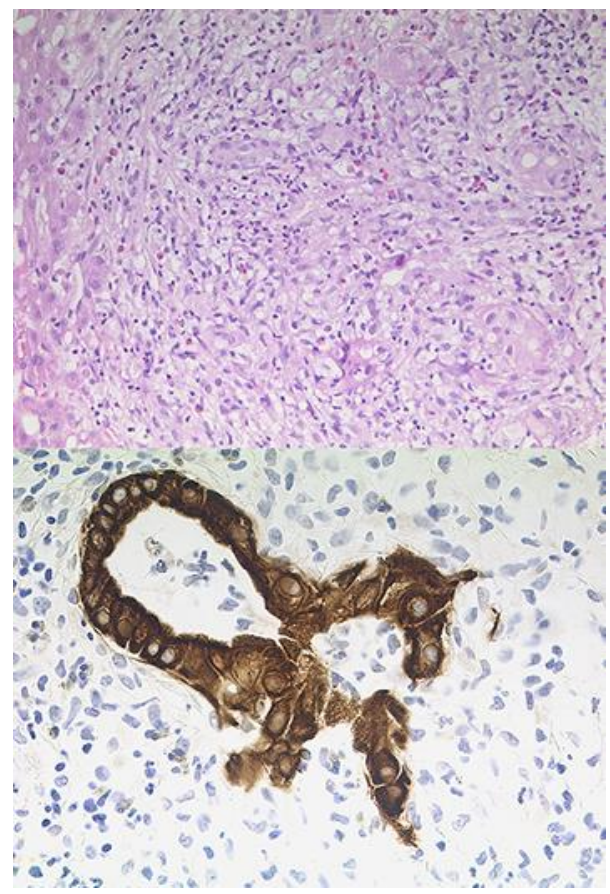

Fig. 3. Magnification of 200-400×, section 1 stained with HE, section 2 after immunohistochemistry against CK7 showing destruction of the bile ducts and the formation of epithelioid cells around the bile ducts.

Table 1. Laboratory findings

\begin{tabular}{llllllll}
\hline & Normal range & $\begin{array}{l}\text { June } \\
2016\end{array}$ & $\begin{array}{l}\text { July } \\
2016\end{array}$ & $\begin{array}{l}\text { August 2016 } \\
\text { treatment } \\
\text { day 1 }\end{array}$ & $\begin{array}{l}\text { August 2016 } \\
\text { treatment } \\
\text { day 4 }\end{array}$ & $\begin{array}{l}\text { March } \\
2017\end{array}$ & $\begin{array}{l}\text { June } \\
2017\end{array}$ \\
\hline $\mathrm{WBC}, / \mathrm{nL}$ & $4-10$ & 10.2 & 6.9 & 7.2 & 8.06 & 8.1 & 6.7 \\
$\mathrm{Hb}, \mathrm{g} / \mathrm{dL}$ & $13.5-17.5$ & 12.4 & 12.3 & 12.1 & 11.9 & 13.1 & 13.0 \\
$\mathrm{ALT}, \mathrm{U} / \mathrm{L}$ & $<50$ & 29 & 27 & 20 & 36 & 23 & 76 \\
$\mathrm{AST}, \mathrm{U} / \mathrm{L}$ & $<50$ & 29 & 25 & 43 & 26 & 34 & 101 \\
$\gamma$-GT, U/L & $<60$ & 229 & 143 & 446 & 194 & 43 & 187 \\
$\mathrm{AP}, \mathrm{U} / \mathrm{L}$ & $40-130$ & 197 & 155 & 354 & 154 & 87 & 175 \\
$\mathrm{Bilimubin,} \mathrm{mg/dL}$ & $0.2-1.2$ & 0.40 & 0.34 & 0.45 & 0.44 & 0.52 & 0.48 \\
$\mathrm{CrP}, \mathrm{mg} / \mathrm{L}$ & $<5$ & 13.6 & 22.5 & 101.6 & 10.5 & 15.2 & 35.0 \\
\hline
\end{tabular}

